\title{
Transient Immune Deficit after Exercise and the Relationship with Immuno-Nutrition: A Short Review of the Literature
}

\author{
Lucas Cecin de Deus Spirandelli ${ }^{1}$, Vítor Brandão Veloso ${ }^{1}$, Eduardo Elias Vieira de Carvalho ${ }^{2}$, \\ Ana Karina Marques Salge ${ }^{3}$, George Kemil Abdalla ${ }^{4}$ and Douglas Reis Abdalla ${ }^{1,4^{*}}$
}

${ }^{1}$ Medicine Course, University of Uberaba, Brazil

${ }^{2}$ Department of Applied Physical Therapy - Federal University of Triângulo Mineiro, Brazil

${ }^{3}$ Faculty of Nursing, Federal University of Goiás, Brazil

${ }^{4}$ Department of Health Sciences, Faculty of Human Talents, Brazil

*Corresponding author: Douglas Reis Abdalla, PhD, Health Sciences Department, Faculty of Human Talents, St. Tonico dos Santos, 333 - São Cristóvão, Uberaba - MG, CEP: 38100-000, Brazil

\begin{abstract}
In order to understand the relationship of immune deficit after physical activity and its relationship with food supplementation with carbohydrates and polyphenols to mitigate this transient suppression, the objective of this review is to identify the factors that characterize the decline in immune function after physical exercise and stress the importance of immunonutrition in this context. The use of carbohydrates and polyphenols in physical activity practitioners to mitigate transient immune deficit. The evidence directs the moment after strenuous physical exercise, as a period in which there is a greater susceptibility to transient immune dysfunctions. There is an increase in numerous metabolites derived from the breakdown of muscle and liver glycogen, as well as an increase in lipids and oxylipins. The function of NK and neutrophil cells, various measures of $T$ and $B$ cell function, production of salivary $\lg \mathrm{A}$, delayed hypersensitivity response of the skin, increased expression of MHC-II in macrophages and other biomarkers of immune function are altered for several hours to days during recovery from prolonged and intensive resistance exercises. To reduce immune dysfunction, there are effective nutritional strategies that include increasing carbohydrate and polyphenol intake. The advantage of this nutritional strategy would also be its positive impact in reducing tissue/systemic inflammation and oxidative stress. Nutritional strategies considered most effective for athletes should include carbohydrates and polyphenols to optimize performance, improve immune activity and aid tissue recovery. The consumption of sugary beverages or fruits promotes a decrease in tissue and systemic inflammation, making the post-exercise environment less impaired from an immunological point of view. In addition, phenolic
\end{abstract}

biotransformers circulate throughout the body, exerting numerous adjuvant effects on athletes, such as combating free radicals, and are beneficial to the general health of individuals.

\author{
Keywords \\ Physical activity, Exercise, Immunology, Nutrition
}

\section{Introduction}

Studies carried out over the years and evidence in the practice of medical clinic point out that the performance of daily physical activities has a positive impact on the health of patients [1]. Among the benefits, we can see: Maintenance or reduction of body weight, combat obesity and related diseases such as Diabetes Mellitus type 2 [2], maintenance of systemic blood pressure [3], improvement in cholesterol levels (LDLHDL) [4], increased mobility and prevention of chronic osteoarticular diseases $[5,6]$.

In contrast, strenuous physical exercise may not produce the same effects when compared to medium/ small effort [7]. Physical exercises of high intensity or of prolonged duration can produce temporary negative effects when analyzing the levels of activity of cells involved in the defense process of the organism. Thus, athletes become susceptible to infections after rigorous training or competitive events [7-12].

Citation: Spirandelli LCD, Veloso VB, de Carvalho EEV, Salge AKM, Abdalla GK, et al. (2020) Transient Immune Deficit after Exercise and the Relationship with Immuno-Nutrition: A Short Review of the Literature. Int J Sports Exerc Med 6:172. doi.org/10.23937/2469-5718/1510172

Accepted: August 24, 2020; Published: August 26, 2020

Copyright: (c) 2020 Spirandelli LCD, et al. This is an open-access article distributed under the terms of the Creative Commons Attribution License, which permits unrestricted use, distribution, and reproduction in any medium, provided the original author and source are credited. 
The tissue recovery process has a high energy demand and therefore the immune system cannot be physiologically effective. In order to reduce the immune deficit, it is evidenced whether the intra- and post-exercise intake of carbohydrates and polyphenols so that their derivatives act in the human body providing a less worn out environment [7].

The purpose of this review is to identify the factors that characterize the decline in immune function after physical exercise and to underline the importance of immunonutrition in this context. The use of carbohydrates and polyphenols in physical activity practitioners to mitigate the transient immune deficit.

\section{Physical Exercise and its Influence on Cellular Metabolism}

Regular aerobic exercise $(<60 \mathrm{~min} /$ intensity/moderate/vigorous) has a general anti-inflammatory influence, which can be identified through biomarkers such as: Tissue macrophages, immunoglobulins, neutrophils, cytotoxic T cells, immature B cells and inflammatory cytokines. These were found in lower levels in adults who have greater aerobic capacity/physical conditioning, due to the performance of activities in a consistent manner [7]. Tissue macrophages have improved antipathogenic activity and in parallel there is an enhanced reduction in immunoglobulins, anti-inflammatory cytokines, neutrophils, NK cells, cytotoxic T cells and immature B cells, which play a critical role in the defense activity of the organism and health. In addition, acute exercises preferentially mobilize NK cells and CD8+ T lymphocytes, which exhibit high cytotoxicity and tissue migration [13-16]. The stress hormones (epinephrine/cortisol) that can suppress the function of immune cells, and the pro-inflammatory cytokines, indicative of intense metabolic activity, do not reach high levels during a short duration and moderate exercise [14]. Exercises acquire extreme relevance when analyzing subgroups such as obese and sick, whose immunovigilance is improved to the detriment of systemic inflammation $[17,18]$. In the long term, the benefits generated by physical exercise are extremely relevant, identified by the improvement in glucose and lipid metabolism and by the continuous exchange of leukocytes between tissues and circulation $[19,20]$.

\section{Transitory Immune Dysfunction before Stren- uous Physical Exercises}

Evidence directs the moment after strenuous physical exercise, as a period when there is a greater susceptibility to transient immune dysfunctions [7]. There is an increase in countless metabolites derived from the breakdown of muscle and liver glycogen, as well as an increase in lipids and oxylipines. The function of NK and neutrophil cells, various measures of $T$ and $B$ cell function, salivary IgA production, delayed skin hypersensitivity response, major expression of histocompatibility complex II in macrophages and other immune function biomarkers are altered by several hours to days during recovery from prolonged and intensive resistance exercises $[12,21]$. Exercise-induced tissue injury/inflammation causes a strong immune response, so immuno-specific proteins are produced to regulate the innate immune response, with oxylipines involved in the initiation, mediation and resolution of this process [22-25]. Sin 1, S100-A8/A12 proteins, catelicidin antimicrobial peptide, a-actinin-1 and profilin-1 are involved in the defense of pathogens and in the chemotaxis and locomotion of immune cells. In parallel, other proteins, including serum amyloid $\mathrm{A}-4$, myeloperoxidase, complement $\mathrm{C} 4 \mathrm{~B}$ and $\mathrm{C} 7$, plasma protease inhibitor $\mathrm{C} 1$, glycoprotein a-2-HS and glycoprotein a-1-acid increase chronically during recovery and are involved in infection response phase [23]. Transient immune dysfunction occurs due to the metabolic changes created, oxidative stress, psychological stress, muscle damage and systemic inflammation, where the cells of the immune system lose the ability to increase oxygen consumption rates, while the recovery process begins. Because of that, tissues become unable to generate enough energy to meet the organism's biosynthetic demands [7].

Immunonutrition: $\mathrm{CHO}$ and Polyphenols and their Effects on the Post-Exercise Immune System

To reduce immune dysfunction, there are effective nutritional strategies that include increased intake of carbohydrates and polyphenols. The advantage of this nutritional strategy would also be its positive impact in reducing tissue/systemic inflammation and oxidative stress [7]. Studies have reported the intake of carbohydrates $(30$ to $60 \mathrm{~g} / \mathrm{h}$ ) during prolonged resistance physical exercises (>90 $\mathrm{min}$ ) resulted in lower levels of stress hormone (epinephrine/cortisol) post-exercise and inflammation [26-28]. 6 to $8 \%$ carbohydrates in drinks or sugar-dense fruits like bananas (added to water) when ingested during physical activity, resulted in higher plasma glucose and insulin levels, lower stress-related hormones, as well as, adenocorticotropic hormone and growth hormone, less mobilization and oxidation of fatty acids and reduced systemic inflammation, measured by biomarkers such as, IL-6, IL-8, IL-1ra, IL-10, RNAm, neutrophil count, monocytes, phagocytosis of granulocytes. The effect of carbohydrate intake on reducing post-exercise inflammation is significant (30 to $40 \%$ ), especially when there is only water intake in nightly fasting athletes $[10,23,29-31]$. Fruits have sugars and a wide variety of polyphenols that will turn into biologically active structures (flavonoids). When ingested they will not be absorbed by the small intestine and when they reach the colon the bacterial degradation will produce phenolics, which will be related to the fight against free radicals.

Biotransformed and reabsorbed phenolics (after 
phase 2 of hepatic conjugation) will have several bioactive effects, such as signaling of anti-inflammatory, antiviral, antioxidant and immunological cells [32-34] When comparing the intake of a $6 \%$ sugary drink with the intake of bananas with water, during prolonged and intense physical exercises, there was an increase of at least 18 fruit-related metabolites. Molecules such as serotonin, dopamine, phenolics and xenobiotics shortly after being ingested, confer anti-inflammatory effects by combating the expression of cyclooxygenase- 2 (COX2) mRNA the next day [23]. Studies support the intake of fruits such as dates, raisins and bananas by athletes during training to provide sugars and polyphenols that will play an important role in metabolic recovery [7].

\section{Conclusion}

Nutritional strategies considered most efficient for athletes should include carbohydrates and polyphenols, to optimize performance, improve immune activity and assist in tissue recovery. The consumption of sugary drinks or fruits promotes a decrease in tissue and systemic inflammation, making the post-exercise environment less impaired from an immunological point of view. The number of neutrophils and circulating monocytes decreases and smaller amounts of stress-related hormones are identified. In addition, biotransformed phenolics circulate through the body, exerting numerous adjuvant effects on athletes, such as combating free radicals, being beneficial to the general health of individuals.

\section{References}

1. Modolo VB, de Mello MT, de Gimenez PRB, Tufik S, M. Antunes HK (2009) Dependência de exercício físico: Humor, qualidade de vida em atletas amadores e profissionais. Rev Bras Med Esporte Niterói 15: 355-359.

2. SILVA, Carlos A. Da, LIMA, Walter C. de. (2002) Efeito Benéfico do Exercício Físico no Controle Metabólico do Diabetes Mellitus Tipo 2 à Curto Prazo. Arq Bras Endocrinol Metab 46: 550-556.

3. Cavalcante MA, Bombig MTN, Luna Filho B, Carvalho ACC, Paola AAV, et al. (2007) Qualidade de vida de pacientes hipertensos em tratamento ambulatorial. Arq Bras Cardiol 89: $245-250$.

4. FAGHERAZZI, Sanmira, DIAS, Raquel da Luz, BORTOLON, Fernanda (2008) Impacto do exercício físico isolado e combinado com dieta sobre os níveis séricos de HDL, LDL, colesterol total e triglicerídeos. Rev Bras Med Esporte 14: 381-386.

5. World Health Organization (1994) Assessment of fracture risk and its application to screening for posmenopausal osteoporosis: Report of a WHO study group. Technical Report Series 843.

6. Johnell O (1996) Advances in osteoporosis: Better identification of risk factors can reduce morbidity and mortality. $J$ Int Med 239: 299-304.

7. Nieman DC, Wentz LM (2019) The compelling link between physical activity and the body's defense system. J Sport Health Sci 8: 201-217.
8. Tvede N, Pedersen BK, Hansen FR, Bendix T, Christensen LD, et al. (1989) Effect of physical exercise on blood mononuclear cell subpopulations and in vitro proliferative responses. Scand J Immunol 29: 383-389.

9. Northoff H, Berg A (1991) Immunologic mediators as parameters of the reaction to strenuous exercise. Int J Sports Med 12: 9-15.

10. Nieman DC (1985) Immune response to heavy exertion. J Appl Physiol 82: 1385-1394.

11. Peake JM, Gatta PD, Suzuki K, Nieman DC (2015) Cytokine expression and secretion by skeletal muscle cells: Regulatory mechanisms and exercise effects. Exerc Immunol Rev 21: 8-25.

12. Peake JM, Neubauer O, Walsh NP, Simpson RJ (1985) Recovery of the immune system after exercise. J Appl Physiol 122: $1077-1087$.

13. Adams GR, Zaldivar FP, Nance DM, Kodesh E, Radom-Aizik $S$, et al. (2011) Exercise and leukocyte interchange among central circulation, lung, spleen, and muscle. Brain Behav Immun 25: 658-666.

14. Nieman DC, Henson DA, Austin MD, Brown VA (2005) Immune response to a 30-minute walk. Randomized Controlled Trial 37: 57-62.

15. Simpson RJ, Kunz H, Agha N, Graff R (2015) Exercise and the regulation of immune functions. Prog Mol Biol TransI Sci 135: 355-380.

16. Turner JE, Spielmann G, Wadley AJ, Aldred S, Simpson RJ, et al. (2016) Exercise-induced B cell mobilization: Preliminary evidence for an influx of immature cells into the bloodstream. Physiol Behav 164: 376-382.

17. Viana JL, Kosmadakis GC, Watson EL, Bevington A, Feehally J, et al. (2014) Evidence for anti-inflammatory effects of exercise in CKD. J Am Soc Nephrol 25: 2121-2130.

18. Ferrandi PJ, Fico BG, Whitehurst M, Zourdos MC, Bao F, et al. (2018) Acute high-intensity interval exercise induces comparable levels of circulating cell-free DNA and interleukin- 6 in obese and normal-weight individuals. Life Sci 202: 161-166.

19. Karstoft K, Pedersen BK (2016) Exercise and type 2 diabetes: Focus on metabolism and inflammation. Immunol Cell Biol 94: 146-150.

20. Pedersen BK (2017) Anti-inflammatory effects of exercise: Role in diabetes and cardiovascular disease. Eur J Clin Invest 47: 600-611.

21. Campbell JP, Turner JE (2018) Debunking the myth of exercise-induced immune suppression: Redefining the impact of exercise on immunological health across the lifespan. Front Immunol 9: 648.

22. Markworth JF, Vella L, Lingard BS, Tull DL, Rupasinghe TW, et al. (2013) Human inflammatory and resolving lipid mediator responses to resistance exercise and ibuprofen treatment. Am J Physiol Regul Integr Comp Physiol 305: 1281-1296.

23. Nieman DC, Gillitt ND, Sha W, Esposito D, Ramamoorthy $S$ (2018) Metabolic recovery from heavy exertion following banana compared to sugar beverage or water only ingestion: A randomized, crossover trial. PLoS One 13: e0194843.

24. Markworth JF, Maddipati KR, Cameron-Smith D (2016) Emerging roles of pro-resolving lipid mediators in immunological and adaptive responses to exercise-induced muscle injury. Exerc Immunol Rev 22: 110-134. 
25. Whitham M, Parker BL, Friedrichsen M, Hingst JR, Hjorth $M$, et al. (2018) Extracellular vesicles provide a means for tissue crosstalk during exercise. Cell Metab 27: 237-251.

26. Nehlsen-Cannarella SL, Fagoaga OR, Nieman DC, Henson DA, Butter-worth DE, et al. (1985) Carbohydrate and the cytokine response to $2.5 \mathrm{~h}$ of running. J Appl Physiol 82 : 1662-1667.

27. Nieman DC, Fagoaga OR, Butterworth DE, Warren BJ, Utter A, et al. (1997) Carbohydrate supplementation affects blood granulocyte and monocyte trafficking but not function after $2.5 \mathrm{~h}$ or running. Am J Clin Nutr 66: 153-159.

28. Henson DA, Nieman DC, Blodgett AD, Butterworth DE, Utter A, et al. (1999) Influence of exercise mode and carbohydrate on the immune response to prolonged exercise. Int $\mathrm{J}$ Sport Nutr 9: 213-228.

29. Nieman DC, Mitmesser SH (2017) Potential impact of nutrition on immune system recovery from heavy exertion: a metabolomics perspective. Nutrients 9: 513
30. Nieman DC, Lila MA, Gillitt ND (2019) Immunometabolism: A multi-omics approach to interpreting the influence of exercise and diet on the immune system. Ann Rev Food Sci Technol 10: 341-363.

31. Nieman DC (1998) Influence of carbohydrate on the immune response to intensive, prolonged exercise. Exerc Immunol Rev 4: 64-76.

32. Kay CD, Pereira-Caro G, Ludwig IA, Clifford MN, Crozier A (2017) Antho-cyanins and flavanones are more bioavailable than previously perceived: A review of recent evidence. Annu Rev Food Sci Technol 8: 155-180.

33. Warner EF, Smith MJ, Zhang Q, Raheem KS, O'Hagan D, et al. (2017) Signatures of anthocyanin metabolites identified in humans inhibit biomarkers of vascular inflammation in human endothelial cells. Mol Nutr Food Res 61: 1700053.

34. Nieman DC, Groen AJ, Pugachev A, Vacca G (2018) Detection of functional overreaching in endurance athletes using proteomics. Proteomes 6: E33. 